\title{
Peertechz
}

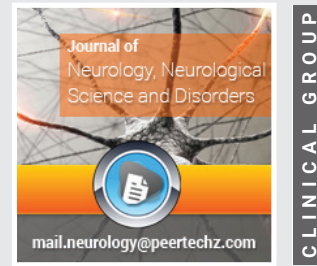

\section{Effects of neck muscle}

\section{vibration on subjective visual vertical in an altered visual frame of reference}

\author{
Christopher A Malaya* and Charles S Layne
}

Check for updates

Center for Neuromotor and Biomechanics Research, University of Houston, Texas and Research Center,

Parker University, Dallas, Texas, USA

Received: 15 September, 2020

Accepted: 12 October, 2020

Published: 15 October, 2020

*Corresponding author: Christopher A Malaya, Department of Health and Human Performance, Center for Neuromotor and Biomechanics Research, University of Houston, Texas and Research Center, Parker University, Dallas, Texas, USA, Tel: 512-827-7466;

Email: christopher.malaya@gmail.com

Keywords: Rod and frame; Subjective visual vertical; Vibration; Perception

https://www.peertechz.com

\begin{abstract}
Rod and Frame Testing (RFT) has been used to investigate the effects of an altered visual frame of reference on subjective visual vertical. RFT requires an individual to align a luminous rod as best they can with true vertical. Their vision, however, is restricted by a rotatable square frame. Muscle vibration has effects on proprioceptive integration and appears to provide the illusion of muscle lengthening. This illusion leads not only to reflexive contractions of the stimulated muscle, but reflexive inhibition of its antagonist. We were interested in examining how the head orientation and perception illusions generated by ventral neck vibration would affect a participant's subjective sense of vertical in an altered visual frame of reference. A sample of 21 healthy individuals between the ages of 18 and 35 undertook RFT with concurrent, unilateral vibration over their sternocleidomastoid muscles. We found that RFT significantly influenced our participants even though their heads were stabilized in a chinrest, with or without vibration. Vibration alone was not significantly different from baseline. We believe this indicates the influence of the close visual frame of the RFT is independent of, or even primary over, relevant somatosensory information as it relates to subjective visual vertical.
\end{abstract}

\section{Abbreviations}

RFT: Rod and Frame Testing; SCM: Sternocleidomastoid muscle; FRVL: Frame Right, Vibration Left; FRVR: Frame Right, Vibration Right; FLVR: Frame Left, Vibration Right; FLVL: Frame Left, Vibration Left

\section{Introduction}

The human sense of vertical (subjective visual vertical) is strongly influenced by inputs from the visual, vestibular and somatosensory systems. Sensory information conveyed by each system is assigned a different "weight" that can vary depending on the individual, the environment, the availability of said information, the task, as well as from unanticipated or abrupt changes in the sensory input stream itself $[1,2]$.

The rod and frame test (RFT) has been used previously to investigate the effects of an altered visual frame of reference on subjective visual vertical $[3,4]$. The RFT requires an individual to align a luminous rod as best they can with gravity (i.e. true vertical). Their vision, however, is restricted by a square frame that can be rotated clockwise or counterclockwise. This provides the individual with an illusory visual frame of reference from which to base their estimation of vertical. Participants' subjective visual vertical (quantified as their error from true vertical) can provide insight into the role of individual sensory systems in perceiving vertical as well as individual participant's reactions to a visual illusion. Previous work has shown that participants' errors are generally in the direction of the frame's orientation [3-5].

Muscle vibration has noted effects on proprioceptive integration, and, by stimulating both primary and secondary muscle afferents, appears to provide the illusion of muscle lengthening [6-8]. Studies by Kawase, et al. and McKenna, et al. have examined the effect of neck muscle vibration on subjective visual vertical, albeit without the any close visual frame of reference. In Kawase, et al. researchers had participants with unilateral vestibular dysfunction sit in a darkened room and rotate a light bar until they perceived it as vertical while receiving vibration over their dorsal neck musculature. They 
found vibration led to significantly larger error in aligning the light bar when it was applied to the side of dysfunction than when applied on the unaffected side [9]. In a similar experiment by McKenna, et al. researchers had healthy adults in a dark room align a laser line with gravitational vertical. Participants' heads were held at 30 degrees of lateral flexion (both to the left and right), as well as in an upright position. While the participants were able to align the laser to vertical under the upright condition, unilateral vibration of the dorsal neck musculature with opposite head tilt significantly affected subjective visual vertical: participants showed significant alignment change towards the direction of vibration [10].

In this study, we were interested in examining how the head orientation and perception illusions generated by ventral neck vibration would affect a participant's subjective sense of vertical in an altered (illusory) visual frame of reference. In this case, as our participant's heads rested on a chin piece, they were unable to move their head in response to the vibratory stimulus. While it is known that the illusory effects of muscle vibration can be diminished by light touch with a static object, we postulated that our participant's sense of vertical might still be affected by the vibratory illusion of self-motion, even without an overt ability to move their head $[11,12]$. In addition, by utilizing an RFT we provided an illusory close visual frame of reference which we believed might influence the effects of the neck vibration. In this way, we aimed to examine the effect of two sensory illusions (one visual modality and the other somatosensory) used in conjunction on an individual's subjective sense of vertical.

\section{Materials and methods}

\section{Participants}

A sample of 21 healthy individuals (38\% female) between the ages of 18 and 35 (mean age: $26.4+/-2.9$ years) volunteered to participate in the study. Participants had no known musculoskeletal, neurological or visual impairments. Written informed consent was obtained from each participant prior to the start of experimental procedures. Approval to conduct this study was granted by the Institutional Review Board at the University of Houston, in accordance with the Declaration of Helsinki.

\section{Experiment}

During the experiment, participants stood in front of a modified version of Oltman's rod and frame apparatus (Oltman 1968) [13]. Each participant rested their chin on an ophthalmological chin rest that was adjusted to center their vision into a 24 " long, 12 " square tunnel. The tunnel rotated around a central axis and their peripheral vision was restricted such that the only reference and visual input they could use was the frame (tunnel) and a monitor at the far end of the frame. The monitor displayed a white rod on a black background that could be rotated using a wireless gamepad controller (Logitech F710 Gaming Controller) held at waist level. Participants were asked to use the controller to align the rod, as best they could, with gravity (i.e. true vertical) over the course of 16 different trials. In between trials, participants were asked to close their eyes while the position of the frame was changed between 18 degrees clockwise, and 18 degrees counterclockwise, where the inclination of the frame has been found to elicit its greatest effect [14]. The starting position of the rod was either 18 degrees clockwise, or 18 degrees counterclockwise relative to the position of the frame, depending on the trial. Prior to testing, participants were provided an opportunity to interact with the gamepad controller to become familiar with the control features Figure 1.

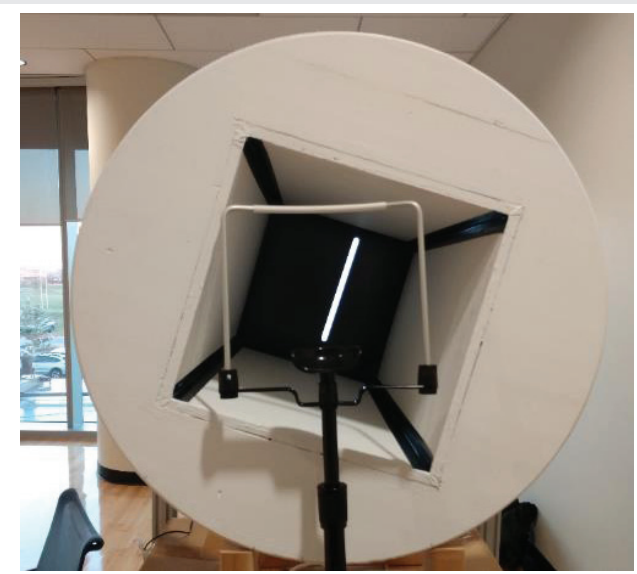

Figure 1: RFT Apparatus.

During 8 of the 16 trials, participants experienced unilateral vibration over one of their sternocleidomastoid muscles (SCM). Participants had small linear motor drivers (Engineering Acoustics, Inc.) adhered bilaterally to their SCMs with medical tape. The linear drivers were controlled by a proprietary software (Engineering Acoustics Tactor SDK 2.10b) and operated with an amplitude of $0.8 \mathrm{~mm}$ at a frequency of $250 \mathrm{~Hz}$.

The 16 trials were organized such that participants had 4 trials with a vertical frame without vibration ("baseline"), 4 trials with a rightward or leftward titled frame and no vibration ("frame only"), 4 trials with a vertical frame and unilateral right-side or left-side SCM vibration ("vibration only", two trials each), and 4 trials with a combination of frame tilt and vibration ("combined"). The 4 combined trials were comprised of two trials with a rightward frame tilt and vibration on the right side or left side (frame right with left vibration: "FRVL"; and frame right with right vibration: "FRVR") as well as two other trials with a leftward frame tilt with right and left vibration ("FLVR" and "FLVL," respectively). The various conditions are identified in Table 1.

Each participant's final rod position and error was recorded by a custom Matlab program (Matlab R2018b:9.5.0.944444).

\section{Statistical analysis}

Data normality was assessed using Shapiro-Wilk and Kolmogorov-Smirnov tests.

As data were not normally distributed, baseline, frame tilt, vibration and combined frame/vibration conditions were 
examined using a related-samples Friedman's test. Post hoc analysis were conducted using Wilcoxon signed-rank tests with Bonferroni correction applied and all post-hoc tests were compared to an adjusted significance value.

\section{Results}

There was a statistically significant difference in baseline, frame, vibration and combined conditions, $\chi^{2}(2)=109.212, p<$ 0.001 Table 2.

The vibration only trials were not statistically different from baseline: vibration on right SCM $(p=0.4)$, vibration on left SCM ( $p=.398)$. The combined frame/vibration conditions were not significantly different from the frame only conditions ( $\mathrm{p}>0.05)$.

Table 1: The various Trial Conditions.

\begin{tabular}{|c|c|c|c|c|}
\hline Trial \# & Trial Condition & $\begin{array}{c}\text { Frame Starting } \\
\text { Tilt }\end{array}$ & Rod Starting Tilt & Vibration Locatior \\
\hline 1 & Baseline & $0^{\circ}$ & $18^{\circ} \mathrm{CW}$ & None \\
\hline 2 & Baseline & $0^{\circ}$ & $18^{\circ} \mathrm{CCW}$ & None \\
\hline 3 & Frame Only & $18^{\circ} \mathrm{CW}$ & $18^{\circ} \mathrm{CW}$ & None \\
\hline 4 & Frame Only & $18^{\circ} \mathrm{CCW}$ & $18^{\circ} \mathrm{CCW}$ & None \\
\hline 5 & Frame Only & $18^{\circ} \mathrm{CW}$ & $18^{\circ} \mathrm{CCW}$ & None \\
\hline 6 & Frame Only & $18^{\circ} \mathrm{CCW}$ & $18^{\circ} \mathrm{CW}$ & None \\
\hline 7 & Vibration Only & $0^{\circ}$ & $18^{\circ} \mathrm{CW}$ & Left SCM \\
\hline 8 & Vibration Only & $0^{\circ}$ & $18^{\circ} \mathrm{CCW}$ & Right SCM \\
\hline 9 & Vibration Only & $0^{\circ}$ & $18^{\circ} \mathrm{CW}$ & Left SCM \\
\hline 10 & Vibration Only & $0^{\circ}$ & $18^{\circ} \mathrm{CCW}$ & Right SCM \\
\hline 11 & Combined (FRVL) & $18^{\circ} \mathrm{CW}$ & $18^{\circ} \mathrm{CW}$ & Left SCM \\
\hline 12 & Combined (FRVR) & $18^{\circ} \mathrm{CCW}$ & $18^{\circ} \mathrm{CCW}$ & Right SCM \\
\hline 13 & Combined (FLVL) & $18 \mathrm{CCW}$ & $18^{\circ} \mathrm{CCW}$ & Left SCM \\
\hline 14 & Combined (FLVR) & $18^{\circ} \mathrm{CW}$ & $18^{\circ} \mathrm{CW}$ & Right SCM \\
\hline 15 & Baseline & $0^{\circ}$ & $18^{\circ} \mathrm{CCW}$ & None \\
\hline 16 & Baseline & $0^{\circ}$ & $18^{\circ} \mathrm{CW}$ & None \\
\hline
\end{tabular}

$\mathrm{CW}=$ Clockwise; $\mathrm{CCW}=$ Counter-Clockwise. All values of Rod Starting Tilt should be added to the Frame Starting Tilt to be compared to true gravitational vertical. For example, in Trial 3 ("Frame Only"), the Frame Starting Tilt is $18^{\circ} \mathrm{CW}$ (this is $18^{\circ}$ from true vertical). However, the Rod Starting Tilt is $18^{\circ} \mathrm{CW}$ from the original position of the frame (this is $36^{\circ}$ from true vertical)

Table 2: Experimental Conditions with Pairwise Comparisons.

Condition Deviation from Vertical (Median \pm SE) Deviation Dir

\begin{tabular}{c|c|c|}
\hline Baseline & $0.25^{\circ} \pm 0.94$ & $\mathrm{CW}$ \\
\hline VR & $0.50^{\circ} \pm 0.25$ & $\mathrm{CW}$ \\
\hline $\mathrm{VL}$ & $0.25^{\circ} \pm 0.22$ & $\mathrm{CCW}$ \\
\hline $\mathrm{FR}$ & $7.00^{\circ} \pm 1.23^{\circ} *$ & $\mathrm{CW}$ \\
\hline $\mathrm{FL}$ & $5.75^{\circ} \pm 1.38^{\circ} *$ & $\mathrm{CCW}$ \\
\hline FRVR & $6.50^{\circ} \pm 1.27^{\circ} *$ & $\mathrm{CW}$ \\
\hline FRVL & $6.00^{\circ} \pm 1.26^{\circ} *$ & $\mathrm{CW}$ \\
\hline FLVR & $7.50^{\circ} \pm 1.43^{\circ} *$ & $\mathrm{CCW}$ \\
\hline FLVL & $7.00^{\circ} \pm 1.49^{\circ} *$ & $\mathrm{CCW}$ \\
\hline
\end{tabular}

Pairwise comparisons made to Baseline Condition: * $p<0.001$
Across all participants, in the frame only conditions, frame right was not significantly different than frame left $(p>0.05)$. In the combined conditions, there was no significant difference between the side of frame tilt and the same side of tilt frame only conditions $(\mathrm{p}>0.05)$.

\section{Discussion}

This study found that participants were strongly affected by the position of a close visual frame when attempting to orient a rod to vertical. Consistent with previous work utilizing an RFT, their errors were most often made in the direction of frame tilt [3-5]. As several investigations have shown the effects of altered close visual frame of reference on subjective visual vertical to be robust through a range of different postures and body orientations, it is little surprise that our participants were likewise affected [3-5]. It is of note, however, that the RFT influenced our participants even though their heads were stabilized in a chinrest. This suggests that the influence of the close visual frame of the RFT is independent of, or even primary over, relevant somatosensory information from the ground and the chinrest as it relates to subjective visual vertical.

The lack of response to neck vibration was likely multifactorial. Malmstrom, et al. has previously shown a lower response to vibration applied to the ventral musculature as compared to dorsal, with stepping-in-place tasks [15]. However, the authors still saw significant change in task with both ventral and dorsal vibration, while the current experiment saw no effect.

It is possible that the haptic contact from the chin rest provided corrective somatosensory information as to offset or overcome the vibratory illusion. This is supported by a study by Bove, et al. which found that light finger touch of a stationary surface reduced body tilt from short duration, single-sided muscle vibration of dorsal neck musculature and the sternocleidomastoid muscle. Similarly, Lackner, et al. [12] reported that haptic contact with a stable bar attenuated center of pressure changes from vibration of the right peroneal tendons in heel-to-toe stance participants. However, Karnath, et al. found significant differences in participant's ability to align a laser pointer with their "subjective straight ahead," in spite of utilizing a chin rest [16]. This suggests the chinrest may not have been solely responsible for disrupting the vibration illusion.

Indeed, it is more likely that the rod and frame device provided enough of a structured visual context as to diminish the effects of the vibratory illusion. This is supported by previous work showing that proprioceptive vibratory stimulation was less impactful in a structured visual environment as compared to darkness $[17,18]$. This suggests that, in the context of the RFT (a structured visual environment), the vibratory illusion was diminished because, even though the close visual reference was conflicting with somatosensory inputs, it was still our participants' primary means of establishing verticality.

Gaerlan, et al. found that healthy adults primarily relied on their visual system for maintaining postural balance [19]. In a study of construction workers at elevation, all measured 
sway parameters significantly increased only when they became distant enough from the ground to lose close visual reference [20]. It has been argued that "appropriate close visual references increase the ability to maintain balance" and that being elevated a distance from the ground removes some of the visual information needed to maintain postural balance [20]. While our study did not have an "appropriate" visual reference (that is, the frame did not accurately represent gravitational vertical), the simple task of standing during an RFT was not challenging enough to induce a fall in our participants and, as there was a close visual reference from the frame, the somatosensory input from the vibratory illusion was not upweighted to counter the conflicted visual input [21].

It is also possible that the somatosensory information from the neck, given altered visual input, was down weighted compared to somatosensory information from the feet. In the Simeonov, et al. study above, the authors found construction workers at elevation relied more heavily on input from the soles of their feet for maintaining balance. In our study, participants stood on a solid floor during the RFT; however, we did not collect any data on nor challenge the stability of our participant's feet as they stood for the test. Future work should examine the possible differences between somatosensory input to the neck musculature and feet as it relates to close and far visual frames of reference.

Thallasinos, et al. [5] explored the differences in trained athletes versus untrained individuals as it related to Achilles tendon vibration during a two-dimensional, digital RFT. Interestingly, they found that trained dancers were more affected by tendon vibration and took longer to adjust to the illusion than untrained individuals. It has been argued that dance training shifts and individual's sensorimotor dominance from visual to proprioceptive [22-34]. While we did not collect any information on the athletic background of our participants, it was the case in our sample that the visual system appeared to be the primary estimator of verticality. While this appears to be dependent on population, it is notable that the RFT used in Thallasinos, et al. [5] did not have a three-dimensional, physical frame. Instead, the rod and frame were displayed on a large screen. It is possible then, that the visual system retains primacy for establishing vertical unless that information stream is actually absent. In Thallasinos et al., the participants were affected by vibration due to the lack of a physical, close referenced frame. Comparatively, in this study, the presence a close visual reference overrode the vibratory illusion. Said another way, in the presence of altered, even incorrect visual information in close reference, the visuals will remain weighted most heavily. More work in this area is needed to examine these effects, however. In particular, future work on this topic should consider enlarging and distancing the frame, and removing any other close, structured visual references, and examining the effects of muscular vibration on subjective visual vertical.

\section{References}

1. Nashner L, Berthoz A (1978) Visual contribution to rapid motor responses during postural control. Brain Res 150: 403-407. Link: https://bit.ly/3dkip50
2. Peterka RJ (2002) Sensorimotor integration in human postural control. Journal of Neurophysiology 88: 1097-1118. Link: https://bit.ly/3nJRntz

3. Isableu B, Ohlmann T, Cremieux J, Amblard B (1997) Selection of spatial frame of reference and postural control variability. Experimental brain research 114 584-589. Link: https://bit.ly/34LPYdb

4. Isableu B, Ohlmann T, Cremieux J, Vuillerme N, Amblard B, et al. (2010) Individual differences in the ability to identify, select and use appropriate frames of reference for perceptuo-motor control. Neuroscience 169: 11991215. Link: https://bit.ly/30WCeuW

5. Thalassinos M, Fotiadis G, Arabatzi F, Isableu B, Hatzitaki V (2018) Sport Skill-Specific Expertise Biases Sensory Integration for Spatial Referencing and Postural Control. Journal of motor behavior 50: 426-435. Link: https://bit.ly/30Z31qP

6. Goodwin GM, McCloskey DI, Matthews PB (1972) Proprioceptive illusions induced by muscle vibration: contribution by muscle spindles to perception? Science (New York, N.Y.), 175: 1382-1384. Link: https://bit.ly/2GG1SO0

7. Burke D, Hagbarth KE, Löfstedt L, Wallin BG (1976) The responses of human muscle spindle endings to vibration during isometric contraction. Journal of Physiology 261: 695-711. Link: https://bit.ly/2GNpY9q

8. Roll JP, Vedel JP, Ribot E (1989) Alteration of proprioceptive messages induced by tendon vibration in man: a microneurographic study. Experimental brain research 76: 213-222. Link: https://bit.ly/3jUWHrA

9. Kawase T, Maki A, Takata Y, Miyazaki H, Kobayashi T (2011) Effects of neck muscle vibration on subjective visual vertical: comparative analysis with effects on nystagmus. European archives of oto-rhino-laryngology : official journal of the European Federation of Oto-Rhino-Laryngological Societies (EUFOS) : affiliated with the German Society for Oto-Rhino-Laryngology - Head and Neck Surgery, 268: 823-827. Link: https://bit.ly/3nFIJfB

10. McKenna GJ, Peng GC, Zee DS (2004) Neck muscle vibration alters visually perceived roll in normals. Journal of the Association for Research in Otolaryngology : JARO 5: 25-31. Link: https://bit.ly/371eXMy

11. Maaswinkel E, Veeger HE, Dieen JH (2014) Interactions of touch feedback with muscle vibration and galvanic vestibular stimulation in the control of trunk posture. Gait \& posture 39: 745-749. Link: https://bit.ly/3doFJ2g

12. Lackner JR, Rabin E, DiZio P (2000) Fingertip contact suppresses the destabilizing influence of leg muscle vibration. J Neurophysiol 84: 2217-2224 Link: https://bit.ly/34UhR2G

13. Oltman PK (1968) A portable rod-and-frame apparatus. Perceptual and moto skills. 26: 503-506. Link: https://bit.ly/3nlxPpt

14. Zoccolotti P, Antonucci G, Spinelli D (1993) The gap between rod and frame influences the rod-and-frame effect with small and large inducing displays. Perception \& Psychophysics 54: 14-19. Link: https://bit.ly/30ZhmU5

15. Malmström EM, Fransson PA, Jaxmar Bruinen T, Facic S, Tjernström F (2017) Disturbed cervical proprioception affects perception of spatial orientation while in motion. Experimental brain research 235: 2755-2766. Link: https://bit.ly/3IGxmSG

16. Karnath HO, Reich E, Rorden C, Fetter M, Driver J (2002) The perception of body orientation after neck-proprioceptive stimulation. Effects of time and of visual cueing. Experimental brain research 143: 350-358. Link: https://bit.ly/2GNqhRC

17. Lackner JR, Levine MS (1979) Changes in apparent body orientation and sensory localization induced by vibration of postural muscles: vibratory myesthetic illusions. Aviat Space Environ Med 50: 346-354. Link: https://bit.ly/3dmUBhL

18. Velay JL, Roll R, Lennerstrand G, Roll JP (1994) Eye proprioception and visua localization in humans: influence of ocular dominance and visual context. Vision research 34: 2169-2176. Link: https://bit.ly/30ZW6xs 
19. Grace Gaerlan M, Alpert PT, Cross C, Louis M, Kowalski S (2012) Postural balance in young adults: the role of visual, vestibular and somatosensory systems. Journal of the American Academy of Nurse Practitioners 24: 375381. Link: https://bit.ly/3jUfFP2

20. Simeonov $\mathrm{P}, \mathrm{H}$ siao H (2001) Height, surface firmness, and visual reference effects on balance control. Injury prevention : journal of the International Society for Child and Adolescent Injury Prevention 7: i50-i53. Link: https://bit.ly/2Frva28

21. Simeonov P, Hsiao H, Powers J, Ammons D, Kau T, et al. (2011) Postural stability effects of random vibration at the feet of construction workers in simulated elevation. Applied Ergonomics 42: 672-681. Link: https://bit.ly/33QJc6I

22. Golomer E, Dupui P (2000) Spectral analysis of adult dancers' sways: sex and interaction vision-proprioception. The International journal of neuroscience 105: 15-26. Link: https://bit.ly/34Pfxdy

23. Luyat M, Ohlmann T, Barraud PA (1997) Subjective vertical and postural activity. Acta psychologica 95: 181-193. Link: https://bit.ly/3k5KMHq

24. Beinert K, Preiss S, Huber M, Taube W (2015) Cervical joint position sense in neck pain. Immediate effects of muscle vibration versus mental training interventions: a RCT. Eur J Phys Rehabil Med 51: 825-832. Link: https://bit.ly/2FkjOrF

25. Bronstein AM (2016) Multisensory integration in balance control. Handbook of Clinical Neurology 137: 57-66. Link: https://bit.ly/2lp5wMJ

26. Čakrt O, Slabý K, Kmet' J, Kolář $P$, Jeřábek J (2016) Subjective visual and haptic vertical in young and elderly. Journal of vestibular research : equilibrium \& orientation 25: 195-199. Link: https://bit.ly/3jTpLzL
27. Eklund G (1972) General features of vibration-induced effects on balance Upsala journal of medical sciences 77: 112-124. Link: https://bit.ly/30UKNGE

28. Forta NG, Morioka M, Griffin MJ (2009) Difference thresholds for the perception of whole-body vertical vibration: dependence on the frequency and magnitude of vibration. Ergonomics 52: 1305-1310. Link: https://bit.ly/2HOESZS

29. Nyborg $H$ (1974) A method for analysing performance in the rod-andframe test. Scandinavian Journal of Psychology 15: 119-123. Link: https://bit.ly/311SjQ

30. Nyborg H, Isaksen B (1974) A method for analysing performance in the rod-and-frame test. II Test of the Statistical Model. Scandinavian Journal of Psychology 15: 124-126. Link: https://bit.ly/2SQYRfX

31. Pettorossi VE, Panichi R, Botti FM, Biscarini A, Filippi GM, et al. (2015) Long lasting effects of neck muscle vibration and contraction on self-motion perception of vestibular origin. Clin Neurophysiol 126: 1886-1900. Link: https://bit.ly/2GVba8C

32. Roll JP, Vedel JP (1982) Kinaesthetic role of muscle afferents in man, studied by tendon vibration and microneurography. Experimental brain research 47 : 177-190. Link: https://bit.ly/30VJK9F

33. Wannaprom N, Treleaven J, Jull G, Uthaikhup S (2018) Neck muscle vibration produces diverse responses in balance and gait speed between individuals with and without neck pain. Musculoskeletal Science \& Practice 35: 25-29. Link: https://bit.ly/2GV6kli

34. Asch SE, Witkin HA (1992) Studies in space orientation. II. Perception of the upright with displaced visual fields and with body tilted. Journal of experimental psychology. General 121: 407-406. Link: https://bit.ly/3iUGI10
Discover a bigger Impact and Visibility of your article publication with

Peertechz Publications
Highlights

* Signatory publisher of ORCID

* Signatory Publisher of DORA (San Francisco Declaration on Research Assessment)

- Articles archived in worlds' renowned service providers such as Portico, CNKI, AGRIS, TDNet, Base (Bielefeld University Library), CrossRef, Scilit, J-Gate etc.

* Journals indexed in ICMJE, SHERPA/ROMEO, Google Scholar etc.

- OAI-PMH (Open Archives Initiative Protocol for Metadata Harvesting)

* Dedicated Editorial Board for every journa

- Accurate and rapid peer-review process

* Increased citations of published articles through promotions

* Reduced timeline for article publication

Submit your articles and experience a new surge in publication services (https://www.peertechz.com/submission).

Peertechz journals wishes everlasting success in your every endeavours.

Copyright: (C) 2020 Malaya CA, et al. This is an open-access article distributed under the terms of the Creative Commons Attribution License, which permits unrestricted use, distribution, and reproduction in any medium, provided the original author and source are credited.

Citation: Malaya CA, Layne CS (2020) Effects of neck muscle vibration on subjective visual vertical in an altered visual frame of reference. J Neurol Neurol Sci Disord 6(1): 030-034. DOI: https://dx.doi.org/10.17352/jnnsd.000040 